\title{
China's Low Carbon Economic Growth Efficiency: an Analysis Involving Carbon Sink
}

\author{
Dalai Ma* \\ School of Management, Chongqing University of Technology, Chongqing 40054, China
}

Received: 26 August 2016

Accepted: 14 December 2016

\begin{abstract}
By establishing an evaluation system of low carbon economic growth efficiency (LCEGE), inclusive of carbon sink, a non-radical DEA model with slacks-based measure (SBM) was used to measure provincial LCEGEs in China during the period from 1998 to 2013. Based on this data, the spatial auto-correlation of Chinese LCEGE was analyzed. Finally, according to the 1998-2013 panel data from 30 provinces across the country, the paper built up a spatial panel data model to conduct empirical research on the factors influencing LCEGE. The research results show that during the sample period, China's provincial LCEGEs differentiate from each other, and the average LCEGE in eastern coastal provinces phenomenally exceeds those of the inland provinces. In terms of the three regions, eastern China witnesses the highest LCEGE, which is followed by western China; and central China was last in the ranking. Moran's I statistic result indicates that provincial LCEGEs have significant spatial auto-correlation and tend to cluster. Factors of industrial structure, energy consumption structure, and government policy exert a remarkably negative effect on LCEGE; while technological innovation, human capital, FDI, and foreign trade lend LCEGE a helping hand.
\end{abstract}

Keywords: low carbon economic growth efficiency, carbon sink, SBM model, spatial panel data model

\section{Introduction}

Since implementation of the reform and opening-up policy, the Chinese economy has experienced a span of rapid growth. The process of a large collection of material wealth also gives rise to severe environmental and energy problems. In 2013, the total energy consumption in the

*e-mail: madalai@163.com country equaled up to 3.75 billion tons of standard coal, accounting for $22.4 \%$ of the world's total. During the same year, China's total carbon emissions occupied 29\% of the global total, which made China's global carbon dioxide ranking higher than the United States for the first time. Therefore, the international society exerted on China unprecedented pressure for carbon emission reduction. Meanwhile, the energy consumption per unit GDP in the country remained at a high level. For example, the unit GDP energy consumption in 2012 was not only 
2.5 times the world average, but also 3.3 times that of the United States, seven times that of Japan, and even higher than Mexico and Brazil over the same period. With respect to EPI, China ranked 116 in 2012, falling by 22 places in comparison to ranking 94 in 2006. In all, China's low carbon economic growth efficiency (LCEGE) was still relatively low in relation to the level of economic development. Therefore, in order to achieve energy savings and emissions reductions, it is of great significance to achieve one of the 13th Five-Year Plan's targets that the national energy consumption volume per unit GDP in 2020 will drop by $40-45 \%$ of the consumption volume in 2005 , and that research will continue into lowcarbon-oriented economic transformation.

For a long time, the economic growth in China has been tagged with "large input, high-energy consumption, phenomenal expansion, heavy pollution, and low efficiency." As a result, economic growth modes have become a research focus at home and abroad. Traditionally, the mere surge in GDP demands greater input of funds, energy, and other factors. As this has already failed to comply with the national requirement of "low carbon society" construction, the country steers toward the growth of total factor productivity (TFP). However, despite plenty of achievements of existing empirical research into the TFP of the Chinese economy [1], the impact of resource and environmental constraints on national economic efficiency is neglected. Such studies only measure expected outputs such as GDP, but overlook $\mathrm{CO}_{2}$ emissions, $\mathrm{SO}_{2}$ emissions, and other undesirable outputs. These research results actually distort both the evaluation of China's LCEGE and understandings of the concept of TFP.

LCEGE is differentiated from traditional economic efficiency in that national or local economic efficiency factors are evaluated only when resource input and environmental costs are taken into consideration. Similar concepts occur with "green economic efficiency," "sustainable growth," and "energy environment efficiency" [2-3]. The TFP definition is a prerequisite for the definition of LCEGE. TFP is the difference between the growth rate of output and the growth rate of factor input, which represents the unexplained part of economic growth and reflects the quality of economic growth [4]. LCEGE is the kind of TFP that considers the constraints of resources and the environment [5]. Specifically, on the one hand LCEGE is an evaluation index of economic efficiency in a locality; on the other hand, in terms of low carbon economic growth, resource input and undesirable output undergo thorough consideration with respect to the way by which resource utilization and environmental costs are incorporated into the process of production.

In recent years, more and more scholars have begun to explore the factors influencing China's TFP in relation to the environment. Wei [6] used the non-parametric Malmquist index to measure China's TFP, and carried out VAR-based empirical research on the influence of trade openness and human resources on TFP. The corresponding result showed that these two factors exerted a remarkable effect on TFP. By taking the environmental factor into account, Yue and Liu [7] analyzed the influencing factors of industrial growth efficiency in China, which were summarized into positive factors (marketization level, FDI, and research innovation) and negative factors (market competition, expenditure on technology introduction, and technological transformation). Wang et al. [8] empirically studied the factors impacting environmental efficiency and environmental TFP growth, and found out that GDP per capita, structural factors, government policy, and environmental awareness carried weight.

Most of the said studies are based on DEA, with which energy, environmental performance and their influencing factors are analyzed from the perspective of TFP. Despite the fact that the above TFP measurement methods take a comprehensive account of labor, input of energy and capital, economic growth, and carbon emissions (carbon source), carbon sink was ignored as another important factor during the process of lowcarbon economy transformation [9]. In the past few years, the central government has intensified the effort to protect bio-environments with active promotion of afforestation and conversion of degraded farmland into forest and grassland. Under the positive response of local governments, afforestation engineering has increased year by year. When the quality of economic growth in different areas is assessed with the mere criterion of carbon emission reduction, it will inevitably mandate such means as brownouts. As a result, the initiative of afforestation will be damaged, to the disadvantage of the transformation of economic development modes in China. Therefore, it is necessary to incorporate carbon sink factors due to afforestation into the evaluation system, so that the TFP growth assessment approach can be ever more fair and effective. Given this, this paper incorporated carbon sink factors due to afforestation into the TFP growth evaluation system, where the SBM model was used to measure the 1998-2013 LCEGEs of 30 provinces in China. On this basis, a spatial econometric model was established. Finally, the factors that influence LCEGE were empirically analyzed.

\section{Material and Methods}

\section{SBM Model}

Using the DEA method to measure the efficiency and productivity of similar decision-making units has proven to be a very effective tool, but the relative efficiency evaluation of DEA requires that the input must be reduced as much as possible, and the output must be expanded as much as possible [10]. These undesirable outputs must be reduced as much as possible in order to achieve the best economic efficiency, while the traditional DEA model can only make it increase, contrary to the original intention of efficiency evaluation. In reality, the production process produces not only good products but often also creates significant by-products, known as the "non-expected 
output." In short, the biggest problem of the traditional DEA model is that it cannot solve the problem of the slacks of input and output. Therefore, this paper chose the SBM model to measure the efficiency of China's lowcarbon economic growth.

The SBM model is essentially the DEA model with a slacks-based measurement that was established by Tone in 2001 [11]. Meanwhile, room for improvement of all input variables and output variables is considered and reflected in an objective function, with the final form of a value between $0-1$.

Assuming that a production system has $n$ decision-making units and $m$ production factors, with the result of s1 desirable outputs and $\mathrm{s} 2$ undesirable outputs, and that the variables $X=\left(x_{1}, x_{2}, \ldots, x_{n}\right) \in R_{+}^{m \times n}$, $Y^{g}=\left(y_{1}^{g}, y_{2}^{g}, \ldots, y_{n}^{g}\right) \in R_{+}^{s \times n}, Y^{b}=\left(y_{1}^{b}, y_{2}^{b}, \ldots, y_{n}^{b}\right) \in R_{+}^{s \times n}$ represent factor input, desirable output, and undesirable output, respectively. If $D M U=\left(x, y^{g}, y^{b}\right)$ denotes the decision-making unit to be measured, then the possible production set is obtained as:

$$
\begin{gathered}
P^{t}(x)=\left\{\left(y^{g}, y^{b}\right), x \text { produce }\left(y^{g}, y^{b}\right) \mid\right. \\
\left.\mid x \geq X \lambda, y^{g} \leq \gamma^{g} \lambda, y^{b} \geq \gamma^{b}, \lambda \geq 0\right\}
\end{gathered}
$$

This equation shows that the production technology model has the following important features: the undesirable output and expected output have weak disposability and zero binding. Inequality constraints show that the inputs and outputs are expected to have strong disposability as well as represent a cross-sectional observation of non-negative weights. Building upon the work of Zhang and Choi [12], we applied the improved SBM model to deal with these features and this process can be described as follows [13]:

$$
\begin{gathered}
\min \quad \rho=\frac{1-\frac{1}{m} \sum_{i=1}^{m} s_{i}^{x-} / x_{i o}}{1+\frac{1}{s_{d}+s_{u}}\left(\sum_{d=1}^{d} s_{d}^{y+} / y_{d o}+\sum_{u=1}^{u} s_{u}^{b-} / b_{u o}\right)} \\
\text { S.t. } \quad x_{0}=\sum_{j=1}^{n} \lambda_{j} x_{i j}+s_{i}^{x-}, i=1,2, \ldots, m \\
y_{0}=\sum_{j=1}^{n} \lambda_{j} y_{d j}-s_{d}^{y+}, d=1,2, \ldots, d \\
b_{0}=\sum_{j=1}^{n} \lambda_{j} b_{u j}+s_{u}^{b-}, u=1,2, \ldots, u \\
\lambda \geq 0, s_{i}^{x-} \geq 0, s_{d}^{y+} \geq 0, s_{u}^{b-} \geq 0
\end{gathered}
$$

... where: $s^{x-} \in R^{m}, s^{y+} \in R^{d}$, and $s^{b-} \in R^{u}$ represent the slack variables of input, desirable output, and undesirable output, respectively. Their positive values represent the respective excessive input, insufficient desirable output, and surplus undesirable output. The numerator in equation $\rho$ indicates the mean reduction ratio of the actual input of production DMU to production frontier, i.e., input inefficiency; while the denominator demonstrates the mean expansion ratio of the actual input of production DMU to production frontier, i.e., output inefficiency. With regards to a certain DMU, the technology is efficient when and only when $\rho=1$, namely $s^{x-}=0, s^{y+}=0$, and $s^{b-}=0$ when $\rho<1$. This means that the DMU is inefficient, and that it can become efficient through the elimination of input slack and output slack. Finally, the SBM model was chosen to calculate the LCEGE of different provinces in China.

\section{Spatial Auto-Regressive Coefficients}

Geospatial effect is the main interactive spatial effect between LCEGEs, which features the geospatial attribute of observations in geographical space. The concept of geospatial effect originates from the theory of spatial economics. The pair of characteristics that reflects geospatial effect are spatial auto-correlation and spatial heterogeneity. Spatial auto-correlation exists in the spatial agglomeration effect of LCEGE generated from the function of spatial spillover and the expansion mechanism of neighboring provinces. Spatial heterogeneity is a phenomenon of spatial outliers that happens when the discrepancies of central regions and phenomenal regions are notable enough as a result of the spatial unevenness of LCEGE. In general, the spatial effect is reflected by Global Moran I, a classic spatial auto-correlation statistic that is derived from Z-score statistics, according to the research method initiated by Moran in 1948 [14]. The specific calculation formula is:

$$
\text { Moran's } I=\frac{n}{\sum_{i=1}^{n}\left(x_{i}-\bar{x}\right)^{2}} \frac{\sum_{i=1}^{n} \sum_{j=1}^{n} W_{i j}\left(x_{i}-\bar{x}\right)\left(x_{j}-\bar{x}\right)}{\sum_{i=1}^{n} \sum_{j=1}^{n} W_{i j}}
$$

...where $W_{i j}$ is the spatial weight matrix, $n$ denotes the number of spatial units, and $x_{i}$ and $x_{j}$ represent the observation values of targeted variables in areas $i$ and $j$, respectively. $\bar{x}=\left(\sum_{i} x_{i}\right) / n$ is the mean value of the observation values. Generally, Global Moran I falls within the interval of $[-1,1]$. When Moran's $I=-1$, the observed variable is totally negatively correlated; when Moran's $I=1$, the observed variable is totally positively correlated; and when Moran's $I=0$, the observed variable is of no spatial correlation.

To identify the authenticity of the obtained Moran's, a significance test should be done. The frequently used test formula is based on the hypothesis of Z-score normal distribution, which is shown as follows:

$$
Z(d)=\frac{[\text { Moran's I }-E(\text { Moran's I })]}{\sqrt{\text { VAR(Moran's I })}}
$$




\section{Spatial Panel Data Models: the Spatial Auto-Correlation Model (SAR) and the Spatial Error Model (SEM)}

The premise of a classic econometric model is the spatial homogeneity and independent identical distribution (iid) of observations, fixed explanatory variables, etc. However, non-spatial econometric models ignore the spatial auto-correlation of residuals when using the least square method for parametric simulation. As a result, there is likely to be large deviations of estimated results from actual results. Therefore, the spatial econometric model is a necessity in addressing problems arising from spatial auto-correlation of observations. Currently, classic spatial econometric models include the spatial auto regression model (SAR) and the spatial error model (SEM). The definition of SAR is [15]:

$$
\left\{\begin{array}{l}
y=\rho W_{1} y+X \beta+u \\
u=\lambda W_{2}+\varepsilon \\
\varepsilon \sim N\left(0, \sigma_{\varepsilon}^{2} I_{n}\right)
\end{array}\right.
$$

...where $y$ is the explained variable; $\rho$ and $\lambda$ are spatial auto-correlation parameters that indicate the degree of spatial dependence of explained variables themselves; $W$ is a $n \times n$ spatial weight matrix, and the most commonly used spatial weight matrix is the 0 and 1 spatial adjacency matrix; $W y$ is the spatial auto-correlation variable; and $\varepsilon$ is the random error.

The definition of SEM is [16]:

$$
\left\{\begin{array}{l}
y=X \beta+\varepsilon \\
u=\lambda W_{1} \varepsilon+\mu \\
\varepsilon \sim N\left(0, \sigma_{\varepsilon}^{2} I_{n}\right)
\end{array}\right.
$$

...where $\lambda$ is the spatial error coefficient at $n \times 1$ order, which indicates the degree of spatial correlation of residues; $\mu$ is the random error that observes normal distribution; and $\beta$ is the regression parameter of the major model that detects the impact effect of $X$ on $y$. It can be seen that the spatial correlation of SEM is reflected by the degree of spatial random error.

Besides, in order to offer efficacious policy suggestions for the improvement of Chinese LCEGE, the influencing factors were chosen from different perspectives including the economy, society, and politics. Meanwhile, given that the employment of OLS estimation that spares spatial effects will cause deviations once provincial LCEGEs are significantly spatially correlated with each other, we preferred the spatial econometric model to analyze the factors influencing the LCEGEs of 30 Chinese provinces. As the data adopted herein was based on the panel data of the 30 provinces, it was necessary to select from fixed effects and stochastic effects during the process of model regression. The fixed effect meant that individual effects exerted greater effect on the regression variables. For the stochastic effect, there was no interlink between individual effects and regression variables. Since the entry point of the empirical research in the paper was individual effects, the fixed effect fit the research better than the stochastic effect did. Finally, based on equation (5) and equation (6), the paper established the fixed-effect-based spatial panel data model, which was expressed as follows:

$$
\begin{aligned}
L C E G E_{i, t}=\alpha_{i}+\phi_{t}+\beta_{1} I S_{i, t}+\beta_{2} T I_{i, t}+\beta_{3} H C_{i, t}+\beta_{4} F D I_{i, t}+ \\
\quad \beta_{5} F T_{i, t}+\beta_{6} E S C_{i, t}+\beta_{7} G P_{i, t}+\delta \sum_{j} W_{i j}\left(L C E G E_{i, t}\right)+\mu_{i, t} \\
\mu_{i, t}=\lambda \sum_{j} W_{i j} * u_{i, t}+\varepsilon_{i, t}
\end{aligned}
$$

This model is a spatial fixed-effect model, where $\delta$ and $\lambda$ denote the spatial auto-correlation coefficient and spatial error coefficient, respectively. If $\delta$ significance is 0 , the model becomes $S E M$; if $\lambda$ significance is 0 , the model switches to SAR. $\alpha_{i}$ and $\phi_{t}$ represent the spatial fixed effect and the time-fixed effect.

\section{Variables and Data Sources}

\section{Variables and Data Sources for SBM}

In recent years, the central government has gradually strengthened its environmental protection work, vigorously carrying out afforestation and reforestation, and the local governments are also acting accordingly. If at the time of evaluation of economic growth efficiency in areas, the focus was only on reducing carbon dioxide reduction, the results would lead local governments to take necessary measures, such as power cuts, etc. In this way, afforestation is bound to be affected, and thus will produce a negative impact on low-carbon economy. Therefore, in the study on low-carbon economy by Lei and Yu [17], they proposed a "forest area" as a major factor in the formation of a "carbon sink" and proposed carbon cycle total factor productivity (CCTFP). Referencing this idea, this paper presents LCEGE, also known as total factor productivity (TFP) of low-carbon economy, whose assessment system contains a section on capital, labor, energy consumption, afforestation, GDP, and $\mathrm{CO}_{2}$. Then, in the perspective of inputs and outputs from the definition of economics, low-carbon economic growth efficiency refers to getting maximum economic output and minimal $\mathrm{CO}_{2}$ without increasing the underlying capital, labor, energy consumption, and afforestation. Compared to the previous TFP evaluation system, the most significant feature of the evaluation system, "afforestation" is considered an undesired input and joined into the assessment system.

In terms of the whole LCEGE evaluation system, the panel data of the 30 provinces was collected from 1998 to 2013 in China. The data on the six variables included capital stock, labor force, energy consumption, afforestation, GDP, and $\mathrm{CO}_{2}$. Capital stock, labor force, energy consumption, and afforestation were input variables. GDP was the desirable output variable, and 
Table 1. Definition of variables for SB.

\begin{tabular}{|c|c|}
\hline Variables & Data compilation \\
\hline Capital stock & $\begin{array}{l}\text { The actual annual capital stock at } 1952 \text { prices, which is measured by the perpetual inventory method } \\
K_{t}=I+(1-\delta) K_{t-1} \cdot K_{t} \text { represents the th-phase capital stock, } I_{t} \text { is the th-phase investment, and } \delta \text { is the th-phase } \\
\text { capital depreciation rate [20]. }\end{array}$ \\
\hline Labor force & Number of persons engaged $(10,000)$. \\
\hline $\begin{array}{c}\text { Energy } \\
\text { consumption }\end{array}$ & $\begin{array}{l}\text { Refers to use of primary energy before transformation to other end-use fuels, which is equal to indigenous } \\
\text { production plus imports and stock changes, minus exports and fuels supplied to ships and aircraft engaged in } \\
\text { international transport. }\end{array}$ \\
\hline Afforestation & $\begin{array}{l}\text { New afforestation area in various forms of forest, shrubwood and other forms, which were formed or restored by } \\
\text { artificial measures. }\end{array}$ \\
\hline GDP & Uses expenditure-side real GDP at chained purchasing power parities (in 100 million at 1952 prices) \\
\hline $\mathrm{CO}_{2}$ & $\begin{array}{l}\text { The amount of } \mathrm{CO}_{2} \text { is calculated according to the UN Framework Convention on Climate Change passed by the } \\
\text { IPCC (2006) and reference methods in Chapter 6, Volume II (Energy) of Guidelines for National Greenhouse } \\
\text { Gas Inventories in the Kyoto Protocol. The specific formula is } \mathrm{CO}_{2}=\sum_{i=1}^{3} E_{i} \times n N C V_{i} \times C E F_{i} \times C O F_{i} \times(44 / 12) \text {. } \\
\mathrm{CO}_{2} \text { denotes the estimated amount of emitted carbon dioxide, } i=1,2,3 \text { denotes that the corresponding equation } \\
\text { represents coal, petroleum, and gas, respectively. E denotes the amount of energy consumption. NCV denotes the } \\
\text { net calorific value of energy, CEF denotes the coefficient of carbon dioxide emissions, COF denotes the oxidant } \\
\text { factor of coal, and } 44 \text { and } 12 \text { denote the molecular weight of carbon dioxide and carbon. }\end{array}$ \\
\hline
\end{tabular}

Table 2. Descriptive statistics of inputs and outputs.

\begin{tabular}{|c|c|c|c|c|c|}
\hline Variables & Unit & Mean & SD & Min & Max \\
\hline Capital stock & $¥ 100$ million & $4,161.72$ & $4,933.71$ & 107.81 & $28,973.40$ \\
\hline Labor force & $10^{4}$ workers & $2,396.12$ & $1,599.91$ & 254.80 & $6,554.30$ \\
\hline Energy consumption & $10^{4}$ tons & $8,134.89$ & $6,559.86$ & 196.50 & $38,592.06$ \\
\hline Afforestation & $10^{3}$ hektares & 178.57 & 175.75 & 0.71 & 907.40 \\
\hline GDP & $¥ 100$ million & $1,848.28$ & $1,847.76$ & 53.58 & $10,059.71$ \\
\hline $\mathrm{CO}_{2}$ & $10^{4}$ tons & $21,063.49$ & $17,161.41$ & 454.95 & $99,367.51$ \\
\hline
\end{tabular}

$\mathrm{CO}_{2}$ was the undesirable output variable. Tibet was not considered due to the unavailability or inconsistency of its data. Data for energy consumption was obtained from the China Energy Statistical Yearbook while data for the other variables came from the China Statistical Yearbook [18-19]. Table 1 provides detailed information on these six variables and Table 2 shows descriptive statistics of the input and output variables.

\section{Variables and Data Sources for Influencing Provincial LCEGES}

LCEGE improvement is the essence of sustainable economic development in China. Research into factors affecting LCEGE functions as a direct and effective promotion for sustainable economic growth in various localities. During their analysis of the steps to sustainable low-carbon economic transformation, Foxon [21] proposed a framework composed of five factors: ecosystem, technology, organization, business strategy, and consumption practice. Pan et al. [22] analyzed the influencing factors of low-carbon economy from four perspectives, namely the development stage, lowcarbon technology, consumption mode, and resource endowment. This paper combined the above research thoughts, and expounded five aspects that the low-carbon economy responded to, including industrial structure, technological advance, opening up, resource endowment, and government policies.

The function mechanism of these was:

Regarding industrial structure. The ratio of secondary industrial output to GDP was used to measure the changing conditions of regional industrial structure. According to Luo and $\mathrm{Li}$ [23], industrial structure change is a crucial beacon to economic expansion, and in particular the change of secondary industry proportion scales the level of economic growth. Compared to primary and tertiary industries, secondary industry has the closest relations with regional carbon emissions. The reason for this is that resource-intensive industries occupy large percentages of secondary industry, which mainly contributes to national carbon emissions as a heavy energy-consuming industry. The increase in the proportion of China's secondary industry will significantly increase the amount of energy consumption. 
Therefore, the industrial structure has a negative effect on China's LCEGE, and it was expected that the variable coefficient symbol would be negative.

Regarding technological advances. For this aspect, a pair of indices was chosen: technological innovation (TI), which referred to the proportion of regional R\&D input in GDP, and human capital (HC), which was the proportion of people with high school certificates or above in the total population. The increment in R\&D input can partly substitute for production factors, thus helping to upgrade industrial structures, reducing regional energy consumption intensity, and enhancing energy consumption efficiency as well. Meanwhile, innovation development benefits the improvement of regional carbon emission reduction capacity because the emission reduction cost in polluted regions can be lowered prominently in order that the coefficient of the technological innovation is anticipated to be positive. The human capital functions in a way that not only improves the competence and skills of workers, but also helps to raise environmental consciousness [24]. Therefore, the coefficient of human capital was also anticipated to be positive.

Regarding opening-up. For this aspect, a pair of indices was chosen: FDI, which is the proportion of foreign direct investment volume in GDP, and foreign trade (FT), which is the proportion of values of input and output in GDP. In a society with an open economy, national economic growth rests not only on technological progress and policies, but also on economic relations with other countries, including FDI and FT. As an integration of capital stock, knowledge, and technologies, the openingup initiatives play an important role in remedying the regional environment in addition to other advantages such as bridging domestic savings gaps, improving foreign trade conditions, and driving economic growth. Grimes and Kento [25] also found that FDI expansion facilitates the introduction and absorption of foreign capital and technologies, which acts positively in reducing regional energy consumption intensities and raising energy utility rates. So a positive value for the coefficient symbol for FDI was expected. As an engine for economic growth, FT is conducive to the progress of domestic resource allocation and technological efficiency. Therefore, the coefficient of FT was also anticipated to be positive.

Regarding resource endowment. This aspect is represented by ECS, the proportion of coal consumption volume with respect to total energy consumption volume. Under the action of resource endowment, energy is consumed on the spot along with its production. As a major coal-based country, China consumes coal in most cases. Compared to clean energies, including hydro, bio, wind, and nuclear, coal belongs to the group of high carbon energy sources. Thus, the greater the proportion of coal consumption accounted for the total energy consumption, and the higher the total amount of carbon emissions in the region, the more negative the coefficient of the variable.

Regarding government policy. The proportion of government fiscal expenditure in GDP was used in this paper to measure the double-edged dynamics of government functions on the environment. On the one hand, adequate government investment helps improve long-term economic growth efficiency, strengthen efforts in pollution control, and further reinforce energy conservation and emission reduction at the regional level. On the other hand, surplus government intervention will distort resource allocation, giving rise to negative effects on economic growth and environmental protection. Government intervention on China's LCEGE may be a positive impact, but may also be a negative impact - the key lies in the role of which mechanism has a stronger effect. Therefore, the coefficient of the variable was anticipated to be uncertain.

This paper examined the impact on changes of LCEGE of the following variables: industrial structure (IS), technological innovation (TI), human capital (HC), foreign direct investment (FDI), foreign trade (FT), energy consumption structure (ECS), and government policy (GP). The descriptions of the variables are listed in Table 3.

Table 3. Description of variables influencing LCEGE.

\begin{tabular}{|c|c|c|c|c|}
\hline Variable name & Variable definition & Units & Expected & Date sources \\
\hline Industrial structure (IS) & $\begin{array}{l}\text { Value of the secondary } \\
\text { industry / Total GDP }\end{array}$ & $\%$ & Negative & \multirow{7}{*}{$\begin{array}{c}\text { China Energy Statistical } \\
\text { Yearbook; China } \\
\text { Statistical Yearbook; } \\
\text { Compilation of Statistics } \\
\text { of } 60 \text { Years in New } \\
\text { China [26]. }\end{array}$} \\
\hline Technological innovation (TI) & R\&D value / Total GDP & $\%$ & Positive & \\
\hline Human capital $(\mathrm{HC})$ & $\begin{array}{l}\text { People with high school certificates / total } \\
\text { people }\end{array}$ & $\%$ & Positive & \\
\hline Foreign direct investment (FDI) & Foreign direct investment volume / Total GDP & $\%$ & Positive & \\
\hline Foreign trade $(\mathrm{FT})$ & Values of input and output / Total GDP & $\%$ & Positive & \\
\hline $\begin{array}{l}\text { Energy consumption } \\
\text { Structure (ECS) }\end{array}$ & Coal consumption / Total energy consumption & $\%$ & Negative & \\
\hline Government policy (GP) & $\begin{array}{l}\text { Government general budget expenditure / Total } \\
\text { GDP }\end{array}$ & $\%$ & Uncertain & \\
\hline
\end{tabular}




\section{Results and Discussion}

\section{Analysis of the Inter-Provincial and Regional Differences in LCEGE}

Based on Formula (2), we ran the SBM in DEA and obtained 30 provincial LCEGEs from 1998 to 2013, as shown in Table 4. According to the mean provincial LCEGE, the first five provinces in the ranking were Liaoning, Yunnan, Fujian, Tianjin, and Shanghai, all of whose mean values exceeded 0.8. They approach the frontier of production functions. The bottom five provinces were Qinghai, Jiangxi, Shanxi, Xinjiang, and Guizhou in sequence. Their mean values were no more than 0.5. As can be seen from this, China's provincial LCEGEs differentiate from each other. Most provinces with high LCEGE were located in eastern coastal areas, while major low-LCEGE provinces were distributed in inland China. A noteworthy fact is that the LCEGE of Yunnan, a western province, remained at a high level for the last few years, and the main cause was that Yunnan itself is agriculture-oriented, with large areas of afforestation.

The results of the above SBM model show that there are great differences in the low-carbon development between different provinces in China. Therefore, in order to promote the development of a low-carbon economy, different provinces should develop a differentiated lowcarbon economy transformation strategy. Provinces such as Jiangxi, Qinghai, Shanxi, Xinjiang, and Guizhou, whose LCEGEs were low, indicate that the economic growth model of "high pollution, high emission, and low efficiency" in these provinces is still deeprooted. Therefore, to achieve low-carbon development, it is urgent for these provinces to focus on implementing energy-saving emissions reduction strategies and realizing the transformation of the economic growth mode. Provinces such as Yunnan, Liaoning, Fujian, Tianjin, and Shanghai had high LCEGE, which indicates that the low-carbon economic development of these provinces was more successful. Given that the level of economic development in different provinces is not the same, for the low level of economic development in Yunnan, to promote low-carbon economy development, the focus should be on accelerating technological progress and optimizing the industrial structure. For the higher level of economic development in Fujian, Liaoning, Tianjin, and Shanghai, it is recommended to strengthen publicity, from improving the environmental awareness of residents to proceed with and further strengthen the transformation of low-carbon economic development.

Table 4 also demonstrates the significant differences in LCEGE among the major regions in China: eastern, western, and central (eastern China includes Beijing, Tianjin, Hebei, Shanghai, Jiangsu, Zhejiang, Fujian, Shandong, Guangdong, Hainan, and Liaoning; central China includes Shanxi, Jilin, Heilongjiang, Anhui, Jiangxi, Henan, Hubei, and Hunan; western China includes Inner Mongolia, Guangxi, Chongqing, Sichuan, Guizhou, Yunnan, Tibet, Shaanxi, Gansu, Qinghai, Ningxia, and Xinjiang). LCEGEs in eastern China were much higher than those in central and western China. From the perspective of average LCEGE in the three economic zones, the mean eastern LCEGE of 0.7848 was higher than the national mean value of 0.6504 , but the mean western and central LCEGE respective values of 0.5498 and 0.5893 were both much lower than the national mean value. The cause of the eastern LCEGE being the highest was that on the one hand, the eastern areas have fully developed their economy, with relatively advanced emission technologies and sensible industry structures; but on the other hand, residents in eastern regions have stronger environmental awareness, and construct more afforestation engineering. Another finding of our research was that western LCEGE surpasses central LCEGE. This is because central areas are largely composed of provinces with strong resource endowments, such as Shanxi and Guizhou (both of which are major provinces for coal manufacturing and coal consumption), which means that the carbon emission levels in these provinces is relatively high. What is more, the industrial structure and ecological protection in western areas are better than central areas of the country.

\section{Spatial Correlation Analysis of Provincial LCEGE}

With the spatial adjacent matrices in formula (3-4) as spatial weight matrices, Geoda software was run to observe the values of provincial LCEGEs from 1998 to 2013. Table 5 shows the Global Moran I index, where all the values have passed the significance test at the $10 \%$ level and are seen to be positive. This result fully shows that the regional LCEGEs in China possess strong and positive spatial auto-correlation, and that spatial auto-correlation plays an important part in the changes of LCEGE in the country. Spatially, LCEGEs are not distributed randomly, but instead cluster together, especially when considering neighboring provinces. At the same time, the Moran I index of LCEGE further reflected the spatial distribution pattern of provincial LCEGE, that is, most of the neighboring provinces showed two strong spatial effects of high- and low-value agglomerations. Therefore, regarding the reality of low-carbon economic development, spatial effect is an important factor that should not be ignored. In view of this, each province should not be regarded as an independent individual land but full attention should be paid to the links with other provinces in the area. Different provinces should break the barriers, further strengthen exchanges and cooperation, realize the complementary advantages of resource endowments, and jointly promote the transformation of low-carbon economic development. Beyond that, if we ignore the significant impact of the spatial effect on LCEGE among provinces, it is possible to get significant deviations in the estimated model. 
Table 4. Provincial LCEGE in China.

\begin{tabular}{|c|c|c|c|c|c|c|c|c|c|}
\hline Year & 1998 & 2000 & 2002 & 2004 & 2006 & 2008 & 2010 & 2012 & Average \\
\hline Beijing & 0.5980 & 0.6258 & 0.6640 & 0.6818 & 0.7301 & 0.7782 & 0.8371 & 0.9252 & 0.7424 \\
\hline Tianjin & 0.7023 & 0.7209 & 0.7522 & 0.8540 & 1.0000 & 0.9296 & 1.0000 & 1.0000 & 0.8789 \\
\hline Hebei & 0.5711 & 0.5691 & 0.5730 & 0.5838 & 0.6089 & 0.6270 & 0.6467 & 0.6543 & 0.6045 \\
\hline Shanxi & 0.4040 & 0.4117 & 0.4208 & 0.4447 & 0.4238 & 0.4319 & 0.4548 & 0.4790 & 0.4372 \\
\hline Inner Mongolia & 0.4565 & 0.4629 & 0.4673 & 0.4490 & 0.4487 & 0.4894 & 0.4906 & 0.4858 & 0.4706 \\
\hline Liaoning & 0.9044 & 0.9192 & 0.9918 & 1.0000 & 1.0000 & 1.0000 & 1.0000 & 1.0000 & 0.9839 \\
\hline Jilin & 0.5655 & 0.5885 & 0.5978 & 0.5880 & 0.6108 & 0.6230 & 0.6197 & 0.6275 & 0.6060 \\
\hline Heilongjiang & 0.4669 & 0.4845 & 0.5287 & 0.5362 & 0.6206 & 0.5555 & 0.5914 & 0.6129 & 0.5497 \\
\hline Shanghai & 0.7481 & 0.7605 & 0.7857 & 0.8128 & 0.8607 & 0.9248 & 1.0000 & 1.0000 & 0.8691 \\
\hline Jiangsu & 0.7162 & 0.6840 & 0.6957 & 0.6956 & 0.6888 & 0.7054 & 0.7151 & 0.7158 & 0.6997 \\
\hline Zhejiang & 0.7221 & 0.7328 & 0.7544 & 0.7540 & 0.7740 & 0.8022 & 0.7865 & 0.7790 & 0.7633 \\
\hline Anhui & 0.6092 & 0.6163 & 0.6269 & 0.6534 & 0.6494 & 0.6414 & 0.6405 & 0.6990 & 0.6430 \\
\hline Fujian & 0.9062 & 0.8973 & 0.9433 & 1.0000 & 0.9355 & 0.8874 & 0.9313 & 0.8667 & 0.9042 \\
\hline Jiangxi & 0.4303 & 0.4513 & 0.4555 & 0.4295 & 0.4300 & 0.4417 & 0.4454 & 0.4584 & 0.4441 \\
\hline Shandong & 0.5943 & 0.6446 & 0.6188 & 0.6101 & 0.6091 & 0.6315 & 0.6515 & 0.6582 & 0.6273 \\
\hline Henan & 0.4917 & 0.4862 & 0.4795 & 0.4590 & 0.4284 & 0.4516 & 0.4588 & 0.4836 & 0.4732 \\
\hline Hubei & 0.6124 & 0.6051 & 0.6071 & 0.6008 & 0.6011 & 0.6409 & 0.6725 & 0.6873 & 0.6294 \\
\hline Hunan & 0.6053 & 0.6461 & 0.6310 & 0.6029 & 0.5770 & 0.5926 & 0.6223 & 0.6574 & 0.6156 \\
\hline Guangdong & 0.7167 & 0.7011 & 0.6991 & 0.7316 & 0.7529 & 0.7535 & 0.7269 & 0.7276 & 0.7264 \\
\hline Guangxi & 0.7132 & 0.7173 & 0.7535 & 0.6975 & 0.6967 & 0.6993 & 0.6512 & 0.6063 & 0.6874 \\
\hline Hainan & 1.0000 & 1.0000 & 0.8009 & 0.8175 & 0.8143 & 0.7421 & 0.7790 & 0.7811 & 0.8335 \\
\hline Chongqing & 0.7630 & 0.7466 & 0.7422 & 0.7699 & 0.7372 & 0.7541 & 0.7926 & 0.8771 & 0.7744 \\
\hline Sichuan & 0.8089 & 0.8369 & 0.8362 & 0.8015 & 0.8296 & 0.8483 & 0.8916 & 1.0000 & 0.8624 \\
\hline Guizhou & 0.3339 & 0.3521 & 0.3499 & 0.3179 & 0.3312 & 0.3543 & 0.3578 & 0.3701 & 0.3460 \\
\hline Yunnan & 1.0000 & 0.9970 & 1.0000 & 1.0000 & 0.8767 & 0.8878 & 0.8757 & 0.9208 & 0.9317 \\
\hline Shaanxi & 0.5081 & 0.5546 & 0.5442 & 0.5412 & 0.5514 & 0.5886 & 0.5981 & 0.6028 & 0.5647 \\
\hline Gansu & 0.4810 & 0.4764 & 0.4612 & 0.4590 & 0.4958 & 0.5117 & 0.5343 & 0.5552 & 0.4989 \\
\hline Qinghai & 0.4655 & 0.4581 & 0.4308 & 0.4207 & 0.4754 & 0.4490 & 0.5003 & 0.4824 & 0.4541 \\
\hline Ningxia & 0.5422 & 0.5698 & 0.4574 & 0.4472 & 0.4289 & 0.4369 & 0.4519 & 0.4675 & 0.4694 \\
\hline Xinjiang & 0.3839 & 0.4043 & 0.4204 & 0.4243 & 0.4180 & 0.4342 & 0.4383 & 0.4415 & 0.4221 \\
\hline East China & 0.7436 & 0.7505 & 0.7526 & 0.7765 & 0.7977 & 0.7983 & 0.8249 & 0.8280 & 0.7848 \\
\hline Central China & 0.5232 & 0.5362 & 0.5434 & 0.5393 & 0.5426 & 0.5473 & 0.5632 & 0.5881 & 0.5498 \\
\hline West China & 0.5869 & 0.5978 & 0.5876 & 0.5753 & 0.5718 & 0.5867 & 0.5984 & 0.6190 & 0.5893 \\
\hline Nationwide & 0.6274 & 0.6374 & 0.6363 & 0.6395 & 0.6468 & 0.6538 & 0.6721 & 0.6874 & 0.6504 \\
\hline
\end{tabular}

Note: Due to limitation of space, only values of LCEGE for the even-numbered years are listed. 
Table 5. Moran I index of LCEGE in China.

\begin{tabular}{|l|l|l|l|l|l|}
\hline Year & Moran I & $E(I)$ & Mean & Sd(I) & Z-value \\
\hline 1998 & $0.1267^{*}$ & -0.0345 & -0.0387 & 0.1190 & 1.3546 \\
\hline 1999 & $0.1263^{*}$ & -0.0345 & -0.0354 & 0.1202 & 1.3378 \\
\hline 2000 & $0.1150^{*}$ & -0.0345 & -0.0429 & 0.1217 & 1.2284 \\
\hline 2001 & $0.1080^{*}$ & -0.0345 & -0.0389 & 0.1185 & 1.2025 \\
\hline 2002 & $0.1229^{*}$ & -0.0345 & -0.0362 & 0.1185 & 1.3283 \\
\hline 2003 & $0.1190^{*}$ & -0.0345 & -0.0384 & 0.1180 & 1.3008 \\
\hline 2004 & $0.1117^{*}$ & -0.0345 & -0.0419 & 0.1166 & 1.2539 \\
\hline 2005 & $0.1557^{*}$ & -0.0345 & -0.0369 & 0.1229 & 1.5476 \\
\hline 2006 & $0.1484^{*}$ & -0.0345 & -0.0321 & 0.1170 & 1.5632 \\
\hline 2007 & $0.1526^{*}$ & -0.0345 & -0.0369 & 0.1203 & 1.5553 \\
\hline 2008 & $0.1641^{*}$ & -0.0345 & -0.0345 & 0.1197 & 1.6591 \\
\hline 2009 & $0.1475^{*}$ & -0.0345 & -0.0374 & 0.1181 & 1.5411 \\
\hline 2010 & $0.1500^{*}$ & -0.0345 & -0.0378 & 0.1190 & 1.5504 \\
\hline 2011 & $0.1341^{*}$ & -0.0345 & -0.0411 & 0.1173 & 1.4373 \\
\hline 2012 & $0.1318^{*}$ & -0.0345 & -0.0424 & 0.1222 & 1.3609 \\
\hline 2013 & $0.1347^{*}$ & -0.0345 & -0.0436 & 0.1224 & 1.3824 \\
\hline
\end{tabular}

*Different tests with $10 \%$ level of significance.

\section{Analysis of Factors Influencing LCEGE}

When performing spatial econometric regression, the applicability of the spatial econometric method should be verified first, and then a choice between SAR and SEM can be made. LMsar statistics and LMerr statistics develop the basis for such verification, i.e. if they are significant, the spatial econometric model will be adoptable. Meanwhile, according to the Monte Carlo simulation findings from Anselin and Ray [27], LMsar statistics and LMerr statistics can be used for selection between SAR and SEM. There are four kinds of fixed effect models: mixture model, spatial fixed effect model, time fixed effect model, and two-way fixed effect model. It is necessary to make a comparison in search of the

Table 6. LM statistical results under different fixed effects.

\begin{tabular}{|c|c|c|c|c|}
\hline Model & Sample & Test & Statistics & P-value \\
\hline \multirow{2}{*}{ Mixture } & \multirow{2}{*}{480} & LM - sar & 2.6351 & 0.0980 \\
\hline & & LM - err & 2.8579 & 0.0830 \\
\hline \multirow{2}{*}{$\begin{array}{c}\text { Spatial Fixed } \\
\text { Effect }\end{array}$} & \multirow{2}{*}{480} & LM - sar & 17.4111 & 0.0000 \\
\hline & & LM - err & 18.4143 & 0.0000 \\
\hline \multirow{2}{*}{$\begin{array}{l}\text { Time Fixed } \\
\text { Effect }\end{array}$} & \multirow{2}{*}{480} & LM - sar & 2.8044 & 0.0887 \\
\hline & & LM - err & 3.8181 & 0.0507 \\
\hline \multirow{2}{*}{$\begin{array}{c}\text { Two-Way Fixed } \\
\text { Effect }\end{array}$} & \multirow{2}{*}{480} & LM - sar & 12.9850 & 0.0003 \\
\hline & & LM - err & 6.7782 & 0.0092 \\
\hline
\end{tabular}

most suitable model as the sample model in the following empirical research. In this light, Matlab 7.11 was adopted to provide the LMsar values and LMerr values for all the models in an attempt to demonstrate which model was more appropriate.

As can be seen from Table 6, all the models had positive LMsar and LMerr values, and they all passed the significance tests at the $1 \%, 5 \%$, and $10 \%$ levels. This result shows that they are all theoretically adoptable. Meanwhile, according to the comparison between LMsar and LMerr statistics, the mixture model, spatial fixed effect model, and the time fixed effect model had slightly smaller LMsar statistics than LMerr statistics, so they fit better with SEM. Similarly, for the two-way fixed effect model with larger LMsar statistics than LMerr statistics, SAR performs better as a spatial model.

The above findings reflect the fact that spatial correlation problems will inevitably occur on variable residuals when non-spatial panel models, inclusive of the variables, undergo regression. Moreover, such problems are basically beyond the scope of OLS, or at least, the OLS estimation result deviates from the actual result. Given this, the maximum likelihood method is recommended to apply to the estimation of spatial econometric models. Finally, the spatial econometric method was used in the paper to reappraise the non-spatial panel data. Table 6 shows the estimation results of spatial models under the said fixed effects.

As can be seen from Table 7, the $W^{*}$ dep.var. statistics and spat.aut. statistics of all of the four fixed-effect models 
Table7. Estimation of the spatial econometric model.

\begin{tabular}{|c|c|c|c|c|c|c|c|c|}
\hline \multirow[b]{2}{*}{ Variables } & \multicolumn{4}{|c|}{$S A R$} & \multicolumn{4}{|c|}{ SEM } \\
\hline & Mixture & $\begin{array}{c}\text { Spatial Fixed } \\
\text { Effect }\end{array}$ & $\begin{array}{l}\text { Time Fixed } \\
\text { Effect }\end{array}$ & $\begin{array}{c}\text { Two-Way } \\
\text { Fixed Effect }\end{array}$ & Mixture & $\begin{array}{c}\text { Spatial Fixed } \\
\text { Effect }\end{array}$ & $\begin{array}{l}\text { Time Fixed } \\
\text { Effect }\end{array}$ & $\begin{array}{l}\text { Two-Way } \\
\text { Fixed Effect }\end{array}$ \\
\hline$I S$ & $\begin{array}{c}-0.3171 * * * \\
(-3.1723)\end{array}$ & $\begin{array}{c}-0.2673 * * * \\
(-5.1604)\end{array}$ & $\begin{array}{c}-0.3304 * * * \\
(-3.2283)\end{array}$ & $\begin{array}{c}-0.1960 * * \\
(-3.5228)\end{array}$ & $\begin{array}{c}-0.3538 * * * \\
(-3.5985)\end{array}$ & $\begin{array}{c}-0.2599 * * * \\
(-5.0299)\end{array}$ & $\begin{array}{c}-0.3554 * * * \\
(-3.5879)\end{array}$ & $\begin{array}{c}-0.2110 * * * \\
(-3.8533)\end{array}$ \\
\hline$T I$ & $\begin{array}{c}-0.0054 \\
(-0.7347)\end{array}$ & $\begin{array}{l}0.0113 * * \\
(2.5062)\end{array}$ & $\begin{array}{c}0.0033 \\
(0.3783)\end{array}$ & $\begin{array}{c}0.0222 * * * \\
(3.2271)\end{array}$ & $\begin{array}{c}-0.0046 \\
(-0.6311)\end{array}$ & $\begin{array}{c}0.0218^{* * *} \\
(4.4909)\end{array}$ & $\begin{array}{l}0.0129 * \\
(1.5112)\end{array}$ & $\begin{array}{c}0.0290 * * * \\
(4.0439)\end{array}$ \\
\hline $\mathrm{HC}$ & $\begin{array}{l}-0.1763 \\
(-1.0362)\end{array}$ & $\begin{array}{c}0.5030^{* * * *} \\
(4.4552)\end{array}$ & $\begin{array}{c}0.0085 \\
(0.0446)\end{array}$ & $\begin{array}{c}0.7519^{* * *} \\
(5.9158)\end{array}$ & $\begin{array}{c}-0.2084 \\
(-1.2724)\end{array}$ & $\begin{array}{c}0.4772 * * * \\
(4.1117)\end{array}$ & $\begin{array}{c}0.0883 * * * \\
(0.5137)\end{array}$ & $\begin{array}{c}0.6801 * * * \\
(5.3314)\end{array}$ \\
\hline FDI & $\begin{array}{c}0.0691 * * * \\
(12.156)\end{array}$ & $\begin{array}{c}0.0045 \\
(1.2192)\end{array}$ & $\begin{array}{l}0.0520 * * \\
(6.7252)\end{array}$ & $\begin{array}{l}0.0070^{*} \\
(1.8316)\end{array}$ & $\begin{array}{l}0.0703 * * * \\
(14.3837)\end{array}$ & $\begin{array}{c}0.0027 * * * \\
(0.7406)\end{array}$ & $\begin{array}{c}0.0499 * * * \\
(6.5772)\end{array}$ & $\begin{array}{l}0.0050^{*} \\
(1.6397)\end{array}$ \\
\hline$F T$ & $\begin{array}{c}0.0118 \\
(0.4760)\end{array}$ & $\begin{array}{c}0.0326^{* *} \\
(1.9530)\end{array}$ & $\begin{array}{c}0.0102 \\
(0.3467)\end{array}$ & $\begin{array}{l}0.0343^{*} \\
(1.7636)\end{array}$ & $\begin{array}{c}0.0185 * * * \\
(0.7566)\end{array}$ & $\begin{array}{l}0.0382 * * \\
(2.0699)\end{array}$ & $\begin{array}{c}-0.0024 \\
(-0.0888)\end{array}$ & $\begin{array}{c}0.0406 * * \\
(2.0038)\end{array}$ \\
\hline ECS & $\begin{array}{c}-0.2197 * * * \\
(-6.9076)\end{array}$ & $\begin{array}{c}-0.1097 * * * \\
(-5.4411)\end{array}$ & $\begin{array}{c}-0.2678 * * * \\
(-8.0568)\end{array}$ & $\begin{array}{c}-0.1009 * * * \\
(-4.9429)\end{array}$ & $\begin{array}{c}-0.2082 * * * \\
(-6.6050)\end{array}$ & $\begin{array}{c}-0.1149 * * * \\
(-5.6904)\end{array}$ & $\begin{array}{c}-0.2479 * * * \\
(-7.7259)\end{array}$ & $\begin{array}{c}-0.1068 * * * \\
(-5.2302)\end{array}$ \\
\hline GP & $\begin{array}{c}0.1728^{* *} \\
(2.1943)\end{array}$ & $\begin{array}{c}-0.1533 * * * \\
(-3.1385)\end{array}$ & $\begin{array}{c}0.0405 \\
(0.2957)\end{array}$ & $\begin{array}{l}-0.1044 * \\
(-1.8559)\end{array}$ & $\begin{array}{c}0.1996 * * * \\
(2.7223)\end{array}$ & $\begin{array}{c}-0.21181 * * * \\
(-4.0485)\end{array}$ & $\begin{array}{c}0.1550 \\
(1.1823)\end{array}$ & $\begin{array}{c}-0.1647 * * * \\
(-2.8110)\end{array}$ \\
\hline $\begin{array}{l}W^{*} \text { dep. } \\
\text { var. }\end{array}$ & $0.0309 *$ & $0.2819 * * *$ & $0.0789 *$ & $0.2630 * * *$ & & & & \\
\hline spat.aut. & & & & & 00399* & $0.3139 * * *$ & $0.1089 * *$ & $0.2449 * * *$ \\
\hline$R^{2}$ & 0.4375 & 0.9562 & 0.4663 & 0.9577 & 0.4369 & 0.9527 & 0.4618 & 0.9549 \\
\hline$L O G-L$ & 281.4154 & 889.3516 & 293.7089 & 898.6014 & 281.8248 & 890.3261 & 296.3865 & 895.9965 \\
\hline
\end{tabular}

Note: data in brackets () is T test value, ${ }^{*}, * *, * * *$ denote the respective $10 \%, 5 \%$ and $1 \%$ significance levels, Matlab 7.11 was used as the model estimation.

in SEM and SAR passed the significance tests at the $1 \%$, $5 \%$, and $10 \%$ levels. This result fully indicated that the spatial effect actually played a vital role in research on the factors influencing LCEGE. The neglect of spatial effect may distort the obtained result. Meanwhile, through comparison, the estimation coefficients of SEM and SAR were similar in value and shared the same sign, which meant that the spatial econometric model could produce results with great stability. The two-way fixed-effect model had the maximum goodness of fit and $\log$ likelihood in contrast to the rest, corresponding to the strongest explanation. The goodness of fit and log likelihood of the two-way fixed-effect model in SAR both exceeded those in SEM. In summary, the SAR twoway fixed-effect model performed the best in achieving the estimation results in relation to spatial econometrics. Therefore, priority should be given to the actual meanings of estimation coefficients based on this model.

First, according to the results, $I S$ exerted a negative effect on LCEGE at the 1\% significance level, which explains the harm to LCEGE that was caused by the increase of the secondary industry ratio. Currently, the secondary industry in the country is still surging as a relatively large proportion of the national economy. Statistics show that in terms of the building blocks of domestic IS, secondary industry output occupies as large as $43.9 \%$ of GDP, while the primary industry output and the tertiary industry output account for $10.0 \%$ and $46.1 \%$ of GDP, respectively [19]. The slow growth in the tertiary industry is a reflection of its low level such that it is lagging far behind the dominant tertiary industries in developed countries. In particular, along with the accelerated progress of industrialization, the constantly developing secondary industry acts and will continue to act as a significant driving force for economic growth. With secondary industry as the major energy-consuming industry, China is at risk of obstructions in energy conservation, emission reduction, and economic growth transformation at the regional level.

Second, TI exerted a greatly positive effect on LCEGE and is therefore a crucial path towards LCEGE improvement. Thanks to the ever-upgrading regional technologies, the energy consumption intensity in the country witnessed a downward trend, with a $90 \%$ recorded reduction over the past 16 years by dropping from 1.61 in 1998 to 0.66 in 2013 [19]. In addition, the importance of technology research and development on the one hand shows technological advances promoting the enterprises' LCEGE to rise, and realizes low-carbon energy consumption substitution step by step; on the other hand, technological progress helps strengthen the local ability to discharge and control pollution. Both of the advantages lead to the constant enhancement of LCEGE.

Third, $H C$ exerted a positive effect on LCEGE at the $1 \%$ significance level, which explains two matters:

The continuously increasing regional human capital levels result in the non-stop rise in skills and competency of workers. Accordingly, workers have access to more 
advanced low-carbon facilities, and the energy utility efficiency and emission reduction capacity of enterprises can be improved as a result.

With higher levels of education, the public have a stronger sense of environmental protection. They cannot only voluntarily preserve the environment, but also intelligently support low-carbon economic growth transformation.

Fourth, FDI had a positive estimation coefficient, and passed the $10 \%$ significance test, which means that the constant FDI attraction can accelerate the transformation of low-carbon economic growth. The ability to draw FDI was increasing continuously. Data shows that FDI has grown from $\$ 45.46$ billion in 1998 to $\$ 117.15$ billion in 2013 , recording a 2.6-times increase over the duration of the study [19]. The incessant injection of FDI aids the enhancement of the ability to reduce industrial emissions. The reasons for this are: on the one hand, FDI attraction is accompanied by the introduction of cutting-edge production technology and advanced industrial management ideas. The affiliated higher-level environmental protection standards have strong demonstration effects such as updating the local industrial carbon-emission standards in the host country. On the other hand, FDI helps companies provide more job vacancies. With more residents employed, the local income level can increase prominently, and a demand for higher environmental quality thus emerges.

Fifth, FT exerted a positive effect on LCEGE at the $10 \%$ significance level. The non-stop FT development generated an influx of advanced foreign low-carbon technologies and management experience, which, if adopted by corporations, will help lower energy consumption intensity. Especially, along with the deepened FT, the trade structure of imports and exports in China has converted from the low-technology, energyintensive composition of primary products to the lowenergy composition of mid-tech products. As a result, FT is not only conducive to decreasing the intensity of energy consumption, but helps regional foreign trade vendors realize the transformation to low-carbon products.

Sixth, ECS exerted a negative effect on LCEGE at the $1 \%$ significance level. In order to reduce and control carbon emissions, countries and regions across the world launched a "green energy revolution," for which novel clean-energy technologies have been actively developed. Developing countries are notably at the forefront of the revolution, although China is still an energy-intensive country that relies largely on fossil energy, especially coal. In 2013, coal consumption accounted for $66.0 \%$ of the total energy consumption volume, while the combined percentage of hydro-energy, nuclear power, and wind energy was merely $9.8 \%$ [18]. Too much reliance on this high-carbon energy will not only increase regional carbon emissions, but it also impedes low-carbon economic transformation for a long time at the national level.

Seventh, GP exerted a negative effect on LCEGE at the $1 \%$ significance level. This double-edged sword caused more economic and environmental problems in
China due to undue intervention. In particular, many local governments have long been GDP-oriented in a way that often prefers heavy investment in highly polluting industries in pursuit of quick results. The local environment continues deteriorating as a consequence. More deeply, undue government intervention in the market economy is a high restriction on the market's role of resource allocation. The failure to realize national low-carbon economic transformation is one of its causes.

\section{Conclusions}

LCEGE improvement is the key to sustainable economic development. With SBM, the provincial LCEGEs from 1998 to 2013 were measured. In contrast to previous TFP measurement studies, the establishment of the LCEGE evaluation system in this paper involves another important factor: carbon sink. Our research also covers the regional difference of LCEGEs and their spatial auto-correlation. Furthermore, by building up a spatial econometric model, the factors influencing LCEGE were also studied. The results showed that most provinces with high LCEGE were located in eastern coastal areas, while major low-LCEGE provinces were distributed in inland China. The spatial auto-correlation Moran I statistic result reflects a strong spatial auto-correlation between regional LCEGEs, and the simulation effect proved to be more intensive for neighboring provinces. Moreover, factors of industrial structure, energy consumption structure, and government policy exerted a remarkably negative effect on LCEGE; while technological innovation, human capital, FDI, and foreign trade provided a boost to LCEGE.

For the realization of sustainable economic development in China, the large amount of $\mathrm{CO}_{2}$ emitted is a heavy obstruction, and the combined measures of carbon emission intensity reduction and LCEGE improvement is therefore a necessary next step. The government should tighten carbon emission constraints by encouraging low-carbon transformation of conventional industrial production and accelerating its progress. This aims to gradually eliminate excess industrial capacity in China. At the same time, the government should intensify the efforts of technology research and development so as to develop favorable platforms for technological innovation, with the provision of related policy environments and technological subsidies. Another suggestion for the government is to promote universal education as a way to instill environmental awareness in the population. Furthermore, the opening-up level should be lifted, with two complementary strategies of raising barriers to FDI and relaxing local trade protectionism. Also, great efforts should be devoted to clean energy development and establishing sound government-leading environmental protection mechanisms. All these measures are helpful for LCEGE enhancement. 


\section{Acknowledgements}

This research was funded by the Science and Technology Research Project of Chongqing Municipal Education Commission (No. KJ1600942), the National Social Science Fund Project (No. BBJL036), and the Spark Plan Fund of Chongqing University of Technology (No. 2015XH26).

\section{References}

1. HU A.G., ZHENG J.H., GAO Y.N., ZHANG N., XU H.P. Provincial technology efficiency ranking with environment factors (1999-2005). China Economic Quarterly. 7 (3), 933, 2008.

2. REILLY J.M. Green growth and the efficient use of natural resources. Energy Economics. 34 (3), S85, 2012.

3. KONDYLI J. Measurement and evaluation of sustainable development: A composite indicator for the islands of the north Aegean region, Greece. Environmental Impact Assessment Review. 30 (6), 347, 2010.

4. CHEN S.Y. Green industrial revolution in China: A perspective from the change of environmental total factor productivity. Economic Research Journal. 45 (11), 21, 2010.

5. WU X. Analysis of green economic efficiency and green total factor productivity. Huazhong University of Science and Technology. 2014.

6. WEI X.H. Dynamic relationship among trade openness, human capital and total factor productivity: Based on Malmquist index and the VAR. World Economy Studies. 28 (3), 9, 2009.

7. YUE S.J., LIU F.H. Economic growth efficiency and its influencing factors under environmental constrains. The Journal of Quantitative \& Technical Economics. 26 (5), 94, 2009.

8. WANG B., WU Y.R., YAN P.F. Environmental efficiency and environmental total factor productivity growth in China's regional economics. Economic Research Journal. 45 (5), 95, 2010.

9. LEI M., YU X. W. Local fiscal expenditure, environmental regulation and the transformation of China's low-carbon economy. Economic Science. 35 (5), 47, 2013.

10. CHARNES A., COOPER W.W., RHODES E. Measuring the efficiency of decision making units. European Journal of Opera-tional Research. 2 (6), 429, 1978.

11. TONE K. Slacks-based measure of efficiency in data envelopment analysis. European Journal of Operational Research. 130 (3), 498, 2001.
12. ZHANG N., CHOI Y. Environmental energy efficiency of China's regional economies: A non-oriented slacks-based measure analysis. Social Science Journal. 50 (2), 225, 2013.

13. CHANG Y.T., PARK H.S., JEONG J.B., LEE J.W. Evaluating economic and environmental efficiency of global airlines: A SBM-DEA approach. Transportation Research Part D Transport \& Environment. 27 (1), 46, 2014.

14. MORAN P.A. The interpretation of statistical maps. Journal of the Royal Statistical Societ. 10 (2), 243, 1948.

15. ANSELIN L. Spatial econometrics: Methods and models. Springer. 1988.

16. HAINING R. Spatial data analysis in the social and environmental sciences. Cambridge University Press. 1993.

17. LEI M., YU X.W. Measurement and mechanism of low carbon economic growth in China: Based on non-expectation DEA and panel VAR analysis. Economic Science. 37 (2), 44, 2015.

18. BUREAU C.S. China Energy Statistical Yearbook. China Statistics Press: Beijing. 1999-2014.

19. BUREAU C.S. China Statistical Yearbook. China Statistics Press: Beijing. 1999-2014.

20. SHAN H.J. Reestimating the capital stock of china: 19522006. The Journal of Quantitative\& Technical Economics. 25 (10), 17, 2008.

21. FOXON T.J. A coevolutionary framework for analysing a transition to a sustainable low carbon economy. Ecological Economics. 70 (12), 2258, 2011.

22. PAN J.H., ZHUANG G.Y., ZHENG Y., ZHU S.G., XIE Q.D. Clarification of the concept of low-carbon economy and analysis of its core elements. International Economic Review. 33 (4), 88, 2010.

23. LUO L.W., LI S.S. Technical effects of FDI and international trade and provincial carbon emission performance in China. Journal of International Trade. 39 (8), 142, 2013.

24. QU X.E. Total factor efficiency differences of $\mathrm{CO}_{2}$ emissions and driving factors in China's inter-provincal: Based on the 1995-2010 years of empirical research. Nankai Economic Studies. 28 (3), 128, 2012.

25. GRIMES P., KENTO J. Exporting the greenhouse: foreign capital penetration and $\mathrm{CO}_{2}$ emissions 1980-1996. Journal of World-Systems Research. 9 (2), 261, 2003.

26. BUREAU C.S. Compilation of Statistics of 60 Years in New China. China Statistics Press: Beijing, China. 2009.

27. ANSELIN L., REY S. Properties of tests for spatial dependence in linear regression models. Geographical Analysis. 23 (2), 112, 1991. 